\title{
MARRIAGE PATTERNS IN MID- NINETEENTH-CENTURY NEW YORK STATE: A MULTIVARIATE ANALYSIS
}

\author{
Maris A. Vinovskis*
}

One of the most important events in an individual's life is the decision to marry. ${ }^{1}$ The age at marriage is often considered as an index of when children are finally accepted as mature adults by their parents and the rest of the community. In most western societies the act of marriage has depended on the ability of the young couple to establish a new household and it usually marks the beginning of raising a family. The age at first marriage and the proportion of the population ever-marrying are also of great importance to the society as a whole, since the marriage pattern determined to a large degree birth rates in the pre-industrial period. Yet family and demographic historians have paid relatively little attention to determinants of the marriage pattern in the United States. Their analyses of marriages have usually been limited to describing existing marriage patterns or to using marriages as intervening variables in their investigations of fertility differentials and trends.

* Maris A. Vinovskis is an associate professor in the Department of History and an associate research scientist at the Center for Political Studies of the Institute for Social Research at the University of Michigan. He is currently on leave and is the Assistant Staff Director of the U.S. House Select Committee on Population.

'This essay was prepared while I was the Rockefeller Fellow in the History of the Family Program at Clark University and the American Antiquarian Society. Computer funds for the analysis of the data were provided by a grant from the Spencer Foundation. I am indebted to Mary Vinovskis for programming assistance for this project.
Individuals in the past have commented on the relationship between marriage patterns and the economic development of the area. As early as 1751 Benjamin Franklin noted in his pamphlet on population that the greater availability of land in America encouraged couples to marry earlier and to have larger families than their European counterparts.

Hence Marriages in America are more general, and more generally early, than in Europe. And if it is reckoned there, that there is but one marriage per annum among one hundred persons, perhaps we may here reckon two; and if in Europe they have but four Births to a marriage (many of their marriages being late) we may here reckon eight, of which if one half grow up, and our marriages are made, reckoning one with another at twenty years of age, our people must at least be doubled every twenty years (Franklin, 1955).

Subsequent historians have generally accepted Franklin's conclusions on the relationship between land availability and the age at marriage. Philip Greven refined this argument by showing how deliberate delays in the legal transmission of land by parents to their children were used in Andover, Massachusetts in the seventeenth and eighteenth centuries to postpone the age at marriage for the younger sons. ${ }^{2}$ In

${ }^{2}$ (Greven, 1970) Though most scholars of the colonial period have accepted Greven's findings on this issue without question, the evidence in his book does not really establish a relationship between the transfer of land from the father to the son and the son's age at marriage. For a critique of Greven's analysis, see Vinovskis, 1971; and Vinorskis, 1974: 2-8. 
addition, other historians have stressed the importance of the sexual imbalance in frontier areas of the United States in accounting for the relatively early age at first marriage of women (see Moller, 1945; Hecht, 1973; Thompson, 1974:21-59). Yet none of these studies has tried to investigate systematically the differences in the marriage patterns in America-particularly beyond the confines of a single community. ${ }^{3}$

This article attempts to remedy our lack of knowledge about determinants of marriage patterns in nineteenth-century America by analyzing differentials in the proportion of women married among counties in New York State in 1845. The antebellum New York State censuses were unusual compared to the other state or federal censuses in that they contained information on the marital status of the population. Though ideally we would like to have data both on the age at first marriage and the proportion of the population married, the New York State censuses only give us information on the latter issue. Though focus on the percentage of women married indicates only one aspect of the marriage pattern, this limitation is minimized by the fact that the age at first marriage and the proportion who married are usually highly correlated. ${ }^{4}$

${ }^{3}$ The best survey of the pattern of marriages in America is still Monahan, 1951. Unfortunately, Monahan does not really analyze the determinants of the pattern of marriages in America; rather, he devotes most of his attention simply to describing those patterns. For a more recent and a more analytical study of marriages today, see Carter and Glick, 1976.

There are some very interesting analyses being done on the determinants of British marriage patterns in the nineteenth century. For example, see Anderson, 1976.

${ }^{4}$ For a very useful discussion of the patterns of marriages in various societies, see Coale, 1971.

\section{Variables Used}

This study is based on the New York State census of 1845 , which provides information on the proportion of women married as well as the socio-economic characteristics of the counties. Though data were available on the town as well as the county level, the analysis confines itself here to the fifty-nine counties, due to the much higher cost of assembling the data by towns and lack of adequate agricultural indices at the town level.

A number of different socio-economic indices were utilized in the preliminary regression runs as independent variables. The final analysis, however, is based on the percentage of women aged sixteen to forty-five who were married at the time of the census as the dependent variables (expressed as $\mathrm{Y}$ ) and the percentage of the population living in towns 5000 and over $\left(X_{1}\right)$, the percentage of the employed population engaged in manufacturing $\left(X_{2}\right)$, the number of improved acres of land per 100 persons engaged in agriculture $\left(X_{3}\right)$, the number of unimproved acres of land per 100 persons engaged in agriculture $\left(X_{4}\right)$, the number of males per 100 females $\left(X_{s}\right)$, the per capita valuation $\left(X_{6}\right)$, and the percentage of the population foreign-born $\left(X_{7}\right)$ as the independent variables.

The New York State census of 1845 does not provide direct information on the percentage of women aged sixteen to forty-five who are married. Instead, we are given data on the number of women aged sixteen to forty-five and the number of married women under forty-five. Since it is reasonable to assume that very few women married before the age of sixteen, we can estimate the proportion married between the ages of sixteen and forty-five from the census data.

Some problems result from using the percentage of women who are married aged sixteen to forty-five as our dependent variable. For one thing, it does not take into account differences in the age structure of 
the population in those counties. Therefore, if a county had a very high percentage of its women aged sixteen to forty-five concentrated in the last ten years of this agegroup, its proportion married would be higher since the proportion of women married generally increases with age. Unfortunately, it is impossible to eliminate this bias because the 1845 census does not provide detailed age categories. But an analysis of the possible extent of the bias introduced by differences in the age structures among the counties suggests that this is not a serious limitation. ${ }^{5}$

Another problem with the data is that it reflects the percentage of women sixteen to forty-five who were married at the time of the census rather than the percentage of women who had ever been married. As a result, widows and divorced women are treated as single women even though they had once been married. To get an idea of the magnitude of this problem, we can examine the marital status of the female population in New York State in 1855, 1865 , and 1875 when the censuses provided information on the percentage of women fifteen and above who were widowed or divorced.

As we can see, approximately six to eight percent of the women aged fifteen and above were widowed or divorced. However, this overstates the proportion of women aged sixteen to forty-five who were widowed or divorced in 1845 since the number of divorces in New York State at that time was quite small and widows tended to be concentrated at ages over

'In order to estimate the possible biases due to differences among the counties in the age-structure of their populations, we estimated the effects of agedifferences by using the more detailed age-categories from the federal census of 1850 and age-specific marital data from the Massachusetts state census of 1885. The results indicated that the differences among New York counties in their age-structure had very little influence on the proportion of women aged sixteen to forty-five who were married.
TABLE 1. MARITAL STATUS OF THE FEMALE POPULATION FIFTEEN YEARS OLD AND OVER IN NEW YORK STATE IN 1855,1865 , AND 1875

\begin{tabular}{|c|c|c|c|}
\hline Year & Single & Married & $\begin{array}{c}\text { Widowed or } \\
\text { Divorced }\end{array}$ \\
\hline 1855 & $37.7 \%$ & $56.4 \%$ & $5.9 \%$ \\
\hline 1865 & $34.3 \%$ & $58.3 \%$ & $7.4 \%$ \\
\hline 1875 & $36.0 \%$ & $56.1 \%$ & $7.9 \%$ \\
\hline
\end{tabular}

forty-five. In addition, as we analyze the data cross-sectionally, any biases due to the counting of widows and divorced women as single are minimized if the proportions of such women are relatively uniform across the counties. As a result, the percentage of women aged sixteen to forty-five who are married is a reasonable index of the differences in the marriage patterns among the residents of these counties.

In analyzing the proportions of women married in New York State in 1845, it would have been desirable to have a comprehensive theoretical model of the determinants of marriages that then could be tested empirically by our data. Unfortunately, such a marriage model does not now exist. Therefore, we have attempted to test a variety of hypotheses that have been advanced as determinants of marriage even though these hypotheses have not been integrated into a single, overall marriage model. ${ }^{6}$

Scholars have usually argued that women marry later and in smaller percentages in urban and industrial communities.

-There have been some recent efforts to develop comprehensive models of the marriage market. For example, see Becker, 1974; and Freiden, 1974. None of these models, however, has been sufficiently developed to be of immediate use to us in our analysis of fertility patterns in mid-nineteenth-century America. There has been some interesting work done on marriage patterns at the household level using a life cycle approach. For example, see Chudacoff, 1978. For a more general discussion of the use of life course analysis for the study of family history, see Elder, 1978; and Vinovskis, 1977a. 
However, there is little agreement on the reasons for this pattern. Some, like Benjamin Franklin, have noted that the higher costs of setting up a household in towns discouraged marriages.

In Cities, where all Trades, Occupations and Offices are full, many delay matrying, till they see how to bear the Charges of a Family; which Charges are greater in Cities, as Luxury is more common; many live single during Life, and Continue Servants to Families, Journeymen to Trades, \&c. hence Cities do not by natural Generation supply themselves with Inhabitants; the Deaths are more than the Births (Franklin, 1955).

Others have asserted that the higher proportion of single women in urban and industrial areas is really only a reflection of the fact that better job opportunities for women in those localities encourage the migration of single women to those communities. Unfortunately, it is impossible to resolve this debate without agespecific marital and migration data. However, we can at least test the accuracy of the belief that there existed a significantly higher proportion of single women in urban and industrial areas. As our index of urbanization of a county, we calculated the percentage of the population living in towns with 5000 or more inhabitants and as our index of industrialization we computed the percentage of the employed population engaged in manufacturing. ?

Franklin cited the greater availability of farmland in America than in Europe as one of the major reasons for the earlier age at marriage and the higher proportion of women ever-marrying in the New World. This idea has been generally accepted by economists such as Yasukichi Yasuba, Colin Forster, G.S.L. Tucker, and Don Leet (Yasuba, 1961; Forster and Tucker,

${ }^{7}$ On the complexities of using urbanization as a concept in historical work, see Williamson, 1965; and Lampard, 1968:110-111.
1972; Leet, 1975). ${ }^{8}$ Yet no one has really tested the proposition of a higher percentage of women married in areas where farmland is more available.

Unfortunately, the New York State census of 1845 does not provide data on availability or type of farmland. The federal census of 1850 does give information on the number of improved and unimproved acres of land at the county level. By assuming that the relative amount of improved and unimproved land in 1845 was approximately the same among the counties as in 1850 , we calculated two different measures of land availability - the number of improved acres of land per 100 persons engaged in agriculture and the number of unimproved acres of land per 100 persons engaged in agriculture. ${ }^{9}$

The sex ratio of the population is of potential importance in accounting for differentials in the proportion of women married since it reflects the availability of marriage partners in a given area. There is considerable disagreement among scholars, however, on the importance of the sex ration in determining fertility or marriage differentials in nineteenth-century America. H. Yuan T'ien has argued that the sex ratio of the population at the state level was very important in accounting for fertility differentials and trends in the first half of the nineteenth century in the United States since it was highly correlated with the age at first marriage and the proportion of women ever marrying ( $T$ 'ien, 1959). On the other hand, Yasuba minimized the importance of the sex ratio.

${ }^{8}$ For a critique of the land availability interpretation of the decline in nineteenth-century American fertility, see Vinovskis, 1978.

${ }^{9}$ For a detailed discussion of the problems associated with defining land availability, see Vinovskis, 1976. 
In conclusion we might say that, although it is reasonable to assume that the sex ratio affected fertility through marriage customs, it is doubtful that it was an important factor in causing interstate differentials in fertility and in reducing fertility over time. Significant positive correlations between the sex ratio and fertility are likely to have been chiefly the result of correlations between these two variables, on the one hand, and one or more other variables, say interstate migration, the degree of urbanization, or the availability of land, on the other (Yasuba, 1961:126-127).

In order to determine the relative importance of the sex ratio in accounting for differentials in the proportion of women married among the counties after controlling for the influence of other socioeconomic factors, we have included the number of males per 100 females as one of the independent variables.

Another factor that might account for differentials in the proportion of married women aged sixteen to forty-five is the general level of an area's economic prosperity. Ruth Dixon's analysis of variations in the age at marriage and the proportions never marrying among countries in 1960 found a strong positive correlation between per capita income and the proportion never marrying in the West, but a weak negative one in the East (Dixon, 1971). Though we also would have liked to use per capita income in our analysis, it was not available. Instead we relied on the per capita valuation of a county as our index of overall wealth.

Finally, studies have generally found a higher percentage of foreign-born women married than native women in the United States. Since the New York State censuses before 1875 did not report the proportions married according to their ethnic origins, it is necessary to look at the 1875 census in order to ascertain the relationship between ethnicity and the percentage of women married.

As we can see, the foreign-born population had a higher percentage of married males and females aged fifteen and above than the native population in 1875 . Therefore, we suspect that our multiple regression analysis will reveal a positive relationship between the proportion of married women aged sixteen to forty-five and the percentage of the population that was foreign-born in 1845 .

\section{Statistical Procedures Used}

Multiple regression analysis allows one to study the linear relationship between any of the independent variables, $X_{1}$ to $X_{7}$, and a dependent variable, $Y$, while taking into consideration the effect of each of the remaining independent variables on the dependent variable. Multiple regression analysis attempts to produce a linear combination of independent variables which correlates as highly as possible with the dependent variable. The underlying mathematical procedure is the use of the linear least-squares method which produces the smallest possible residual between the predicted value of the dependent variable from the regression equation and its actual value. In addition, multiple regression analysis minimizes problems due to ratio correlation. ${ }^{10}$

${ }^{10}$ For an introduction to multiple regression analysis, see Draper and Smith, 1966; Hays, 1963:490-577; Kerlinger and Pedhazur, 1973; and Blalock, 1960:326-358.

TABLE 2. PERCENTAGE OF THE POPULATION FIFTEEN YEARS OLD AND OVER EVER-MARRIED IN NEW YORK STATE IN 1875

\begin{tabular}{|c|c|c|c|c|c|}
\hline \multicolumn{2}{|c|}{ Native } & \multicolumn{2}{|c|}{ Foreign-Born } & \multicolumn{2}{|c|}{ Total } \\
\hline Male & Fermale & Male & Female & Male & Female \\
\hline $54.5 \%$ & $60.8 \%$ & $74.0 \%$ & $76.2 \%$ & $61.5 \%$ & $66.3 \%$ \\
\hline
\end{tabular}


TABLE 3. SUMMARY STATISTICS

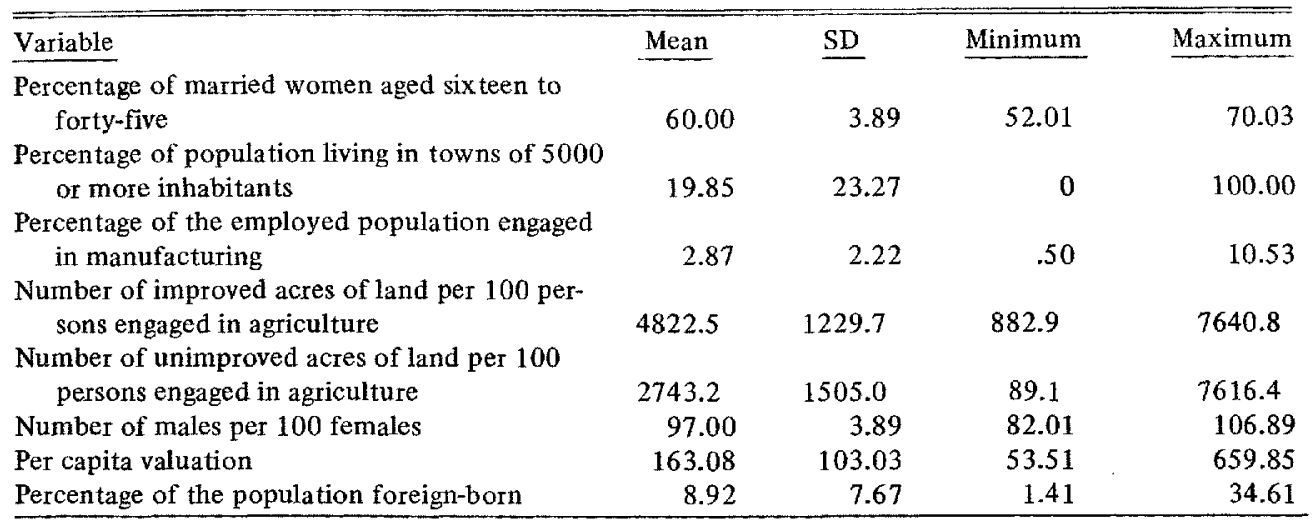

The relationship between two variables is not always linear. Thus, even though the coefficient of linear correlation between two items may be quite low, it does not necessarily mean there is little or no association between them since that relationship might be curvilinear rather than linear. To investigate this possibility, each of the independent variables were plotted against the dependent variable and examined for nonlinearity. In addition, each independent variable was transformed into $\mathrm{LOG}_{10}$ and then correlated with the percentage of women aged sixteen to forty-five who were married to see if it provided a better fit. On the basis of this investigation, it was discovered that per capita valuation should be converted to $\mathrm{LOG}_{10^{\circ}}$.

Due to the small number of cases involved, there was always the danger that two or more of the independent variables would be highly correlated with each other. As multiple regression analysis is based on the assumption that no linear dependence exists between the explanatory variables, the existence of multicollinearity among the variables would invalidate our results. Therefore, care was taken not to include any independent variables which were highly correlated with each other. ${ }^{11}$

${ }^{11}$ Multiple regression analysis assumes that the independent variables are not highly correlated
Finally, in an effort to see whether the presence of some highly urbanized counties have strongly affected the results, the regression analysis was repeated with the omission of the five most urbanized counties. However, as the results of that analysis were almost identical to those covering all of the fifty-nine counties, this paper only presents the statistics for the runs based on all of the New York counties in 1845 .

\section{Results}

The mean, standard deviation, and the minimum and maximum values for each of the variables are presented below in table 3 .

The regression equation for this analysis was calculated in the form:

$$
\begin{aligned}
Y= & a+b_{1} X_{1}+b_{2} X_{2}+b_{3} X_{3}+b_{4} X_{4}+b_{5} X_{5} \\
& +b_{6} L^{2} G_{10} X_{6}+b_{7} X_{7}
\end{aligned}
$$

The results of the regression analysis of the determinants of the percentage of married women aged sixteen to forty-five in New York State in 1845 are summarized in the Appendix (below, 00).

Though regression coefficients indicate the effect of each of the independent vari-

among themselves. For handling this problem, see Johnston, 1972:159-168; and Blalock, 1963:233-238. 
ables on the dependent one, it is impossible to evaluate the relative importance of each variable on the basis of the regression coefficients, as independent variables are measured in different units. Therefore, it is necessary to calculate standardized regression coefficients (beta coefficients) since they indicate the relative importance of the independent variables. (See Appendix.)

On the basis of the beta coefficients, the number of unimproved acres of land per 100 persons engaged in agriculture and the percentage of the population foreign-born were positively related to the percentage of married women aged sixteen to forty-five; while the percentage of the population living in towns of 5000 or more inhabitants, the percentage of the employed population engaged in manufacturing, the number of improved acres of land per 100 persons engaged in agriculture, the number of males per 100 females, and the per capita valuation were negatively related.

In terms of the relative ability of the independent variables to account for differentials in the percentage of married women aged sixteen to forty-five, the number of improved acres of land per 100 persons engaged in agriculture, the number of unimproved acres of land per 100 persons engaged in agriculture, and the number of males per 100 females were particularly strong. The percentage of the population foreign-born was moderately strong whereas the percentage of the population living in towns of 5000 or more inhabitants, the percentage of the employed population engaged in manufacturing, and the per capita valuation were weakly related to the dependent variable.

We also need to look at the overall effectiveness of the resultant regression equation in explaining the dependent variable. Probably the most useful measure of this is adjusted $R^{2}$ - the ratio between the variance of the dependent variable explained by the independent variables and the total variance of the dependent variable. Thus, if the independent variables perfectly predict the values of the dependent variable, the adjusted $R^{2}$ would be equal to one. On the other hand, if the independent variables have no relationship to the dependent variable and therefore are not helpful in predicting values of the dependent variable, the adjusted $R^{2}$ would be equal to zero. The value of the adjusted $\mathrm{R}^{2}$ in this analysis was .6031. In other words, approximately sixty percent of the variance in the proportion of married women aged sixteen to forty-five can be explained by the seven independent variables employed.

\section{Discussion of Results}

Before we begin our discussion of the significance of our results, it is appropriate to note the limitations of this investigation. We analyzed differentials in the proportion of married women aged sixteen to forty-five at the county level. As a result, we cannot assume that our explanations of the differences at the county level will also apply at the individual level. Furthermore, we are unable to ascertain how much of the differences in the proportion of women married among counties was due to agespecific migration rates and how much of it was due to the pattern of marriages within those counties. Despite these shortcomings, however, it is likely that our findings do reflect much of the impact of social and economic factors on the pattern of marriages at the individual level in New York State in 1845. ${ }^{12}$

As we anticipated, the percentage of married women aged sixteen to forty-five was negatively related to the percentage of the population living in towns of 5000 or more inhabitants and the percentage of

${ }^{12} \mathrm{On}$ the problems of making inferences about individuals from aggregate, ecological data, see Alker, 1969:69-86; Vinovskis, 1977b. 
the employed population engaged in manufacturing. What was surprising is the weakness of that relationship. Once we take into consideration the effects of factors such as the sex ratio of the population, the percentage of the population foreignborn, etc. on the differences in the proportion of women married, the degree of urbanization and industrialization of a county contributes relatively little to explaining the marriage patterns. Perhaps one of the reasons that the effects of urbanization and industrialization on marriages have been stressed so much in the past is because these processes were usually highly correlated with other socioeconomic factors, important in predicting the proportion of women who were married. ${ }^{13}$ Yet the casual observer who did not have the benefit of detailed data and sophisticated techniques of analysis could not readily differentiate the relative importance of these factors. ${ }^{14}$

This study confirms the importance of the availability and the type of farmland in determining the proportion of women married. Two of the three most important variables in accounting for the differentials in the percentage of women married were the number of improved acres of land per person engaged in agriculture and the number of unimproved acres of land per person engaged in agriculture. ${ }^{\text {is }}$

${ }^{13} \mathrm{On}$ the problems of the use of urbanization by historians in other areas, see Kaestle and Vinovskis, unpublished paper.

${ }^{14}$ It is quite common that contemporary observers do not perceive correctly the behavioral patterns in their own society. For an example of this in regard to the levels of mortality, see Vinovskis, 1976b.

${ }^{15}$ It is important to note that a study of the determinants of fertility differentials among New York counties in 1845 found that fertility levels were moderately, positively related to the availability of unimproved farmland. Though the direction of that
The direction of the relationship between land availability and the proportion of women married was also as predicted. The greater the amount of unimproved acres of land per person engaged in agriculture in a county, the higher the percentage of married women aged sixteen to forty-five. This is not surprising, as the number of unimproved acres of land per person engaged in agriculture is in part a reflection of the relative ease of obtaining land to establish a new household. It is, however, much more difficult to interpret the strong negative relationship between the number of improved acres of land per person in agriculture and the proportion of women married. Perhaps the number of improved acres of land per person engaged in agriculture is simply a reflection of the more settled agricultural areas where economic opportunities for young couples were less available. On the other hand, we might have expected a more positive relationship since parents who possessed a greater acreage of improved land might have been better able to assist financially their offspring in setting up new households. ${ }^{16}$

Contrary to Yasuba's hypothesis that the sex ratio of the population would have very little significance in accounting for the proportion of the population married once we controlled for other socioeconomic variables, we found that the sex ratio was the single best predictor of the differentials in the percentage of married women aged sixteen to forty-five. This reinforces our findings from the analysis of fertility differentials in the United States

relationship was as anticipated, its strength was much less than predicted by many of the economic historians working in this area; see Vinovskis, $1976 \mathrm{c}$.

${ }^{16}$ For a more detailed discussion of the problems of measuring land availability, see Vinovskis, 1976a. 
in 1850 and 1860 and among Massachusetts townships in 1860 that the sex ratio of the population was one of the best predictors of fertility differentials even after controlling for the influence of other socioeconomic factors (Vinovskis, 1976a; and Vinovskis, forthcoming b). Though the sex ratio of the population is an important factor in accounting for differentials in fertility and in the proportion of women married, we do agree with Yasuba's contention that it was not a major factor in explaining the secular decline in fertility in the United States in the first half of the nineteenth century since the overall changes in the sex ratio of the population were not large enough to account for the sizeable decrease in fertility levels throughout the country.

On the basis of previous studies, we had anticipated that the relationship between the percentages of married women and the per capita valuation of the area would be strongly positive since there would be a greater tendency to marry in counties which were more prosperous. The results, however, did not support our hypothesis since that relationship was actually weak and negative. Perhaps it is an indication that our index of wealth, the per capita valuation, is inadequate due to gross inequities in the tax structure; or, perhaps that the relationship between the wealth of an area and the proportion of women married is not highly correlated in nineteenth-century America. Though this study cannot resolve this dilemma, we suspect that other studies may still find a strong, positive relationship between economic opportunity and the proportion of women marrying. The crucial problem is how to define and measure economic opportunity. Indices of the general wealth of an area based on per capita valuations may not adequately portray the actual opportunities for young people. Instead, we need to try to measure economic conditions and opportunities that particularly relate to the young adult population. For example, in this study we used the number of unimproved acres of land per 100 persons engaged in agriculture as an index of the relative availability of farmland for young couples. Future research may be able to devise additional ways of ascertaining the opportunities for young adults in different sectors of the economy.

Finally, we tested the idea that foreignborn women married in higher proportions than their native counterparts. Our analysis confirmed this hypothesis since we found a positive relationship between the percentage of the population that was foreign-born and the proportion of married women aged sixteen to forty-five.

All of these explanations of the variations in the proportion of married women in New York State in 1845 are plausible individually as well as collectively. Nevertheless, the results of this analysis should be regarded as tentative hypotheses that are intended to stimulate further research rather than as a definitive model of the determinants of marriages in midnineteenth-century America. Future research on marriage patterns should analyze data at individual and household levels as well as state and county levels. Then it will be possible to ascertain more precisely the relationships among individual, family, and community factors in determining the pattern of marriages in the past.

\section{BIBLIOGRAPHY}

\footnotetext{
Alker, Hayward Jr.

1969 "A Typology of Ecological Fallacies." In Mattei Dogan and Stein Rokkan, eds. Quantitative Ecological Analysis in the Social Sciences. Cambridge, Mass.

Anderson, Michael

1976 "Marriage Patterns in Victorian Britain: An Analysis Based on Registration District Data for England and Wales, 1861." Journal of Family History 1:55-78.
} 
60 鱼

Becker, Gary S.

1974 "A Theory of Marriage: Part II." Journal of Political Economy 82:11-26.

Blalock, Hubert M., Jr.

1960 Social Statistics. New York.

1963 "Correlated Independent Variables: The Problem of Multicollinearity." Social Forces 62:233-238.

Carter, Hugh and Paul C. Glick

1976 Marriage and Divorce: A Social and Economic Study. Cambridge, Mass. Revised edition.

Chudacoff, Howard

1978 "The Non-Private Newlyweds: Familial Extension in the First State of the Family Cycle, Providence, Rhode Island, 18641865 and 1879-1880." In Tamara K. Hareven and Maris A. Vinovskis, eds., Demographic Processes and Family Organization in Nineteenth-Century American Society. Princeton.

Coale, Ansley, J.

1971 "Age Patterns of Marriage." Population Studies 25:193-214.

Dixon, Ruth B.

1971 "Explaining Cross-Cultural Variations in Age at Marriage and Proportions Never Marrying." Population Studies 25:215-233.

Draper, N. R. and H. Smith

1966 Applied Regression Analysis. New York.

Elder, Glen H., Jr.

1978 "Family History and the Life Course." In Tamara K. Hareven, ed., Family Transitions and the Life Course in Historical Perspective. New York.

Forster, Colin and G. S. L. Tucker

1972 Economic Opportunity and White American Fertility Ratios: 1800-1860. New Haven.

Franklin, Benjamin

1955 "Observations Concerning the Increase of Mankind, Peopling of Countries, etc." In William Clarke, ed., Observations on the Late and Present Conduct of the French with Regard to their Encroachments Upon the British Colonies in North America. Boston.

Freiden, Alan

1974 "The United States Marriage Market." Journal of Political Economy 82:34-53.

Greven, Philip J., Jr.

1970 Four Generations: Populations, Land, and Family in Colonial Andover, Massachusetts. Ithaca, New York.

Hays, William L.

1963 Statistics. New York.

Hecht, Irene

1973 "The Virginia Muster of $1624 / 5$ as a Source for Demographic History." William and
Mary Quarterly, 3rd Series, 30:65-92.
Johnston, J.
1972 Econometric Methods. New York, second
edition.

Kaestle, Carl F. and Maris A. Vinorskis

"From One Room to One System: The Impact of Urbanization on Educational Development in Nineteenth-Century Massachusetts." Unpublished paper.

Kerlinger, Fred N. and Elazar J. Pedhazur

1973 Multiple Regression in Behavioral Research. New York.

Lampard, Eric E.

1968 "The Evolving System of Cities in the United States: Urbanization and Economic Development." In Harvey S. Perloff and Lowdon Wingo, Jr., eds., Issues in Urban Economics. Baltimore.

Leet, Don

1975 "Human Fertility and Agricultural Opportunities in Ohio Counties: From Frontier to Maturity, 1810-1860." In David C. Klingaman and Richard K. Veddar, eds., Essays in Nineteenth-Century Economic History: The Old Northwest. Athens.

Moller, Herbert

1945 "Sex Composition and Correlated Cultural Patterns of Colonial America." William and Mary Quarterly, Third Series, 2:113153.

Monahan, Thomas $\mathbf{P}$.

1951 The Pattern of Age at Marriage in the United States. Philadelphia, 2 vols.

Thompson, Roger

1974 Women in Stuart England: A Comparative Study. London.

T'ien, H. Yuan

1959 "A Demographic Aspect of Interstate Variation in American Fertility, 1800-1860." Milbank Memorial Fund Quarterly 37:4959.

Vinovskis, Maris A.

1971 "American Historical Demography: A Review Essay." Historical Methods Newsletter 4:141-148.

1974 "The Field of Early American History: A Methodological Critique." The Family in Historical Perspective 7:2-8.

1976a "Socio-Economic Determinants of Interstate Fertility Differentials in the United States in 1850 and 1860 ." Journal of Interdisciplinary History 6:375-396.

1976b "Angels' Heads and Weeping Willows: Death in Early America." Proceedings of the American Antiquarian Society 86:273302. 
1976c Demographic History and the World Population Crisis. Chester Bland-Dwight E. Lee Lectures in History. Worcester, Mass.

1977a "From Household Size to the Life Course: Some Observations on Recent Trends in Family History." American Behavioral Scientist (winter).

$1977 b$ "Problems and Opportunities in the Use of Individual Level and Aggregate Level Census Data." Paper presented at the Conference on Quantification and Methods in Social Science Research, Cologne, Germany (August).

1978 "Recent Trends in American Historical Demography: Some Methodological and Conceptual Considerations." Annual Reviews in Sociology. forth- Demographic Changes in America from the

com- Revolution to the Civil War: An Analysis of ing a the Socio-Economic Determinants of Fertility Differentials and Trends in Massachusetts from 1765 to 1860 . Academic Press.

forth- "A Multivariate Regression Analysis of com- Fertility Differentials Among Massachusetts ing b Towns in 1860." In Charles Tilly, ed., Historical Studies of Changing Fertility. Princeton.

Williamson, Jeffrey $G$.

1965 "Antebellum Urbanization in the American Northeast." Journal of Economic History 25:595-596.

Yasuba, Yasukichi

1961 Birth Rates of the White Population in the United States, 1800-1860: An Economic Study. The Johns Hopkins University Studies in Historical and Political Science 79:2. Baltimore.

\section{APPENDIX}

\section{REGRESSION AND BETA COEFFICIENTS}

\begin{tabular}{lcc}
\hline & $\begin{array}{c}\text { Regression Coefficients } \\
\text { (Standard Errors Given in Percentages) }\end{array}$ & Beta Coefficients \\
\cline { 2 - 3 } Percentage of the population living in towns & -.0118 & -.0705 \\
of 5000 or more inhabitants & $.0221)$ & -.0507 \\
Percentage of the employed population engaged & -.0889 & -.3215 \\
$\quad$ in manufacturing & $(.1567)$ & -.2760 \\
Number of improved acres of land per 100 & -.0010 & -.4453 \\
persons engaged in agriculture & $(.0003)$ & -.0890 \\
Number of males per 100 females & -.0007 & $(.0003)$ \\
LOG 10 of the per capita valuation & -.4449 & $(.1170)$ \\
Percentage of the population foreign-born & -1.4935 & $(1.8939)$ \\
Constant & 108.9746 & $(12.7806)$ \\
\hline
\end{tabular}

